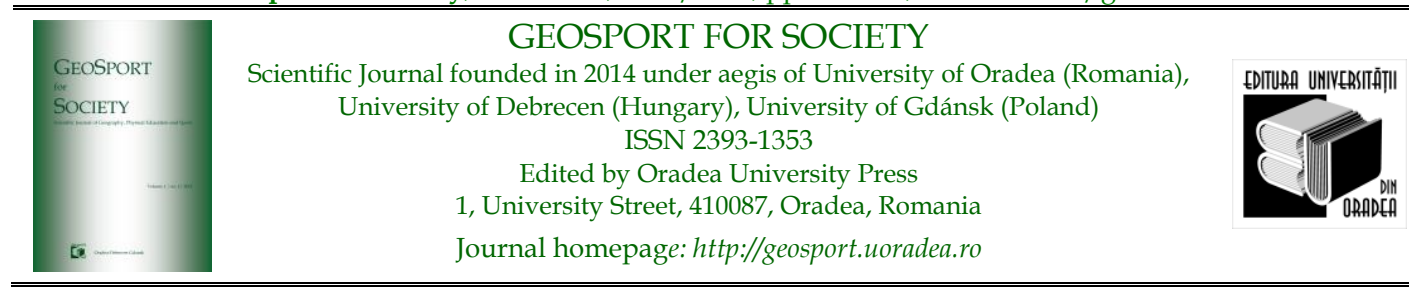

\title{
Kinematic angular analysis of cinematic biomechanics in forearm flexion: a case study
}

\author{
Dan Alexandru SZABO ${ }^{*}$, Nicolae NEAGU ${ }^{1}$, Ioan Sabin SOPA²
}

1. George Emil Palade University of Medicine, Pharmacy, Science, and Technology, Romania, Address: Str. Gheorghe Marinescu, No. 38, C.P. 540139, Târgu Mureṣ, Romania, e-mails: dan-alexandru.szabo@umfst.ro, nicolae.neagu@umfst.ro

2. University "Lucian Blaga" Sibiu, Faculty of Science, Department of Environmental Science, Physics, Physical Education and Sport, Address: Str. Dr. Ion Raţiu, No. 5-7, Sibiu, C.P. 550012, Romania, e-mail: sabin.sopa@ulbsibiu.ro

\section{* Corresponding author}

Citation: Szabo, D.A., Neagu, N., \& Sopa, I. S. (2020). Kinematic angular analysis of cinematic biomechanics in forearm flexion: a case study. Geosport for Society, 13(2), 140-148. https://doi.org/10.30892/gss.1305-065

Article history: 20.10.2020; Revised: 20.11.2020; Accepted: 03.12.2020, Available online: 09.12.2020

\begin{abstract}
The research highlighted the importance of kinesiology and biomechanical analysis of movement in nowadays sports performance. Our case study followed a biomechanical structure of movement of forearm flexion and extension regarding angle, angular velocity, angular acceleration, tangential velocity, centripetal acceleration, resultant acceleration. As a research method, the Kinovea program, version 0.9.3., is used for biomechanical analysis using some specific kinesiological parameters of movement. The biomechanical movement results highlighted the specific forearm flexion and extension, showing the entire movement from a specific angle and speed.
\end{abstract}

Keywords: biomechanical movement, kinesiology, movement of the arm

\section{Introduction}

More generally, sports or physical activities positively impact life quality (Taborri et al., 2020). The benefits of life satisfaction, health, well-being, and educational and social participation have been shown by several studies (Bailey et al., 2015; Gilchrist and Wheaton, 2016). Also, perhaps due to the growing number of people who compete in various sports and recreational levels, the elite level requirements are continually increasing. Recent technological developments have contributed to these growing competitive levels, with these devices being used to monitor sports training and competition performance, particularly from sports biomechanics. The science of sports biomechanics provides quantitative (and sometimes qualitative) evaluations of sports 
performance, particularly sports movements' kinematics and kinetics (Zatsiorsky, 2007). Measuring and characterizing human movements during sporting activities is crucial for coaching programs to evaluate athletes' performance, improve technique, and prevent injuries (Taborri et al., 2019; Lee and James, 2015; Kos and Umek, 2019). Biomechanics represents applying mechanical principles to living organisms, such as humans, animals, plants, and the basic functional units of life of cells. Biomechanics is now widely recognized to play an essential role in understanding the fundamental principles of human motion (Innocenti, 2018).

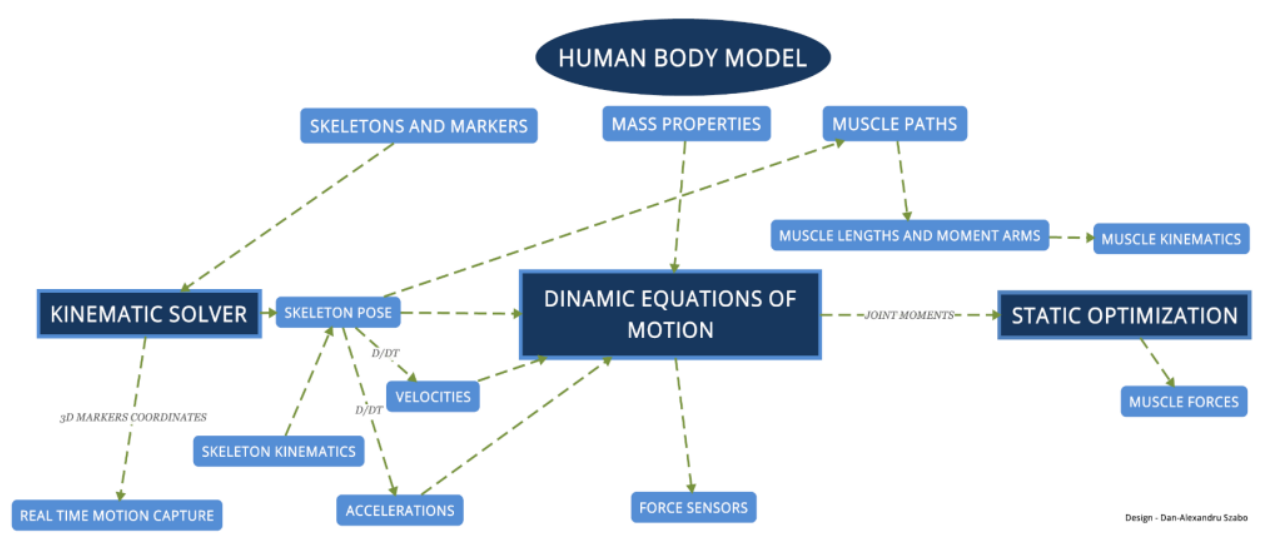

Figure 1. The human body model

(Source: Van den Bogert et al., 2013)

A separate modular organization has been revealed by locomotor networks, where the production from various interconnected supraspinal areas interacts with neuron assemblies located in the spinal cord to produce locomotor patterns and rhythms (Kiehn, 2016; Nordin et al., 2017). Spinal circuits show an amalgam of afferent links that appear to simplify the locomotor's function, given the difficulty associated with neural signal decoding. Rhythmic alternation during locomotion is enabled by relationships among the left section and right sections of the physique and among flexor muscle and extensors (Kiehn, 2016; Lanuza, 2004; Nordin et al., 2017). Commissural neurons with axons in the spinal cord's ventral part that cross the body's midline allow bilateral communication (Kiehn, 2016; Lanuza, 2004; Nordin et al., 2017).

Biomechanics analysis is also used for injury prevention, and three-dimensional motion analysis techniques evaluate joint kinematics and kinetics. These mechanical risk factors preceding ACL rupture can be used to analyze which athletes are most susceptible to injury before onset (Hewett et al., 2017); in particular, with 78 percent sensitivity and 73 percent specificity, knee abduction moment predicted ACL injury status (Hewett et al., 2005).

Human movement biomechanical analysis has become an essential instrument for introductory study and clinical treatment of orthopedic and neurological disorders (Van den Bogert et al., 2013). Traditionally, clinical movement analysis is carried out offline by processing raw motion and force data previously recorded; thus, the clinician who makes treatment decisions makes a laboratory or gait study. Biomechanical unpredictable time heritages such as joint curves (Kinematics) and 
moments (Kinetics) are characteristically clinically significant knowledge in the statement (Van den Bogert et al., 2013). Musculoskeletal prototypes possess appeared employed in modern periods to provide further data about muscle length changes (Arnold et al., 2006) and muscle forces (Delp et al., 2007; Erdemir et al., 2007; Heintz and Gutierrez, 2007; Van den Bogert et al., 2013).

Employing real-time approximated specific variables, such as a particular joint curve (Barrios, 2011) or a particular joint moment (Shull, 2011; Van den Bogert et al., 2013), traditional implementations have appeared established for feedback preparation. Guesstimates that overlook particular mechanical consequences, such as inertial stipulations in the movement calculations, are often used to produce realmoment calculation plausible (Shull, 2011; Van den Bogert et al., 2013). Real time enterprise networks are presently restricted to kinematic elements (joint angles) (Barrios, 2011; Teran-Yengle et al., 2011; Van den Bogert et al., 2013), and perhaps joint moments muscle elements do not encompass them. Though curves and moments may be a helpful substitute for orthopedic or neurological rehabilitation-relevant substance loads and muscle employment, muscle-level analysis is necessary to fully understand (Delp et al., 2007; Erdemir et al., 2007; Van den Bogert et al., 2013). However, this is computationally demanding because, in favor of all muscles in a branch, or definitively, in the integrated body, muscle powers should be determined contemporaneously (Delp et al., 2007; Erdemir et al., 2007; Van den Bogert et al., 2013).

\section{Methodology}

\section{Study Design and Subjects}

The research protocol was explained, and the subject's informed consent for analyzing the results and publishing the paper was obtained. All the procedures have been carried out in compliance with the Helsinki Declaration's requirements.

This research started from the hypothesis that by using kinetic and biomechanical analysis software, Kinovea, version 0.9.3., we will improve the teaching process in the practical work on Biomechanics and Kinesiology discipline.

The study case focused on analyzing the arm's biomechanical angular movement on a student's forearm in the 1st year at the Master's program Physical Therapy and Functional Rehabilitation at the George Palade University of Medicine, Pharmacy, Science, and Technology from Târgu Mureș, Romania.

The purpose of this research was to highlight the fact that it can obtain some biomechanical data, such as angular kinematics, only with the help of video analysis software, without any other means of support.

All analyses were carried out in the framework of practical work in the Biomechanics and Kinesiology discipline, from 16-th September 2020 to 28-th September 2020, at the Discipline of Human Movement Sciences headquarters.

\section{Procedure}

Research protocol included several trials of execution of the arm's flexion on the forearm being registered the best and correct technical execution. The software used for analyzing the arm movement was Kinovea, version 0.9.3. 


\section{Results}
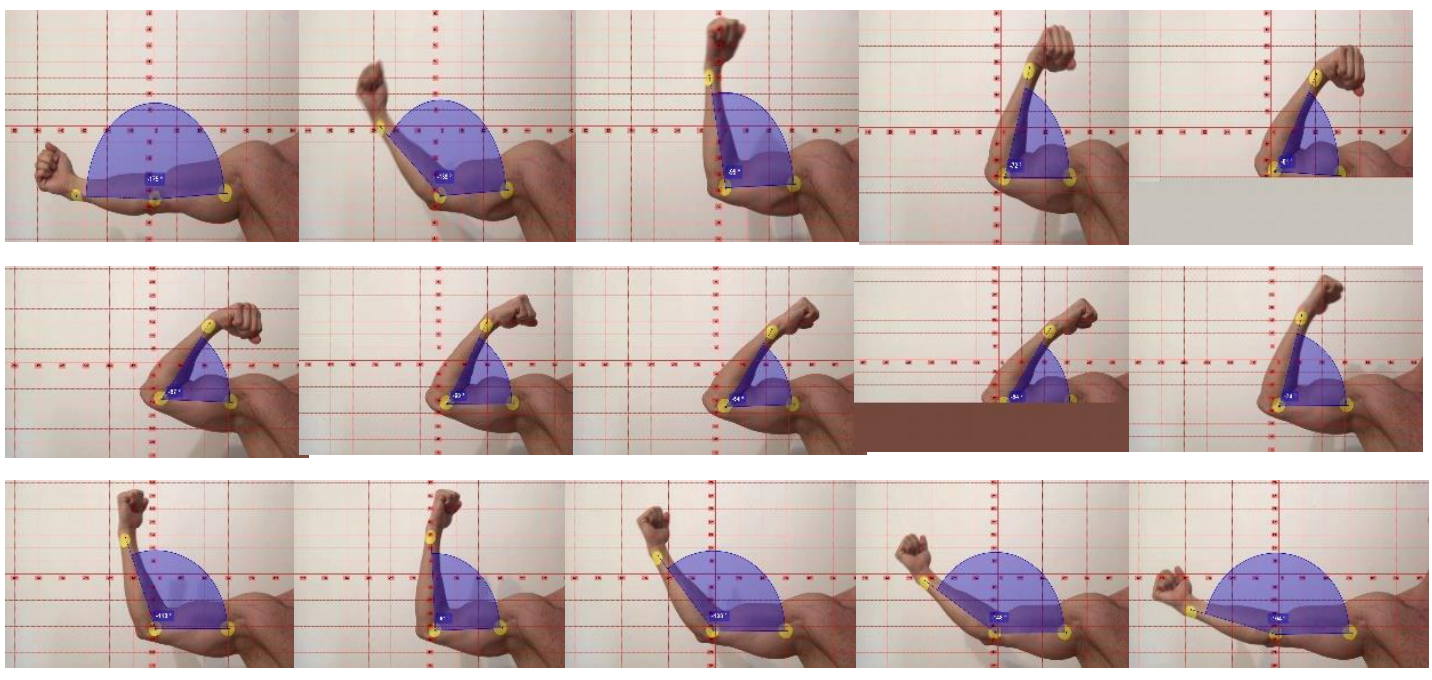

Figure 2. Graphical representation of angle variation in the forearm flexion and extension

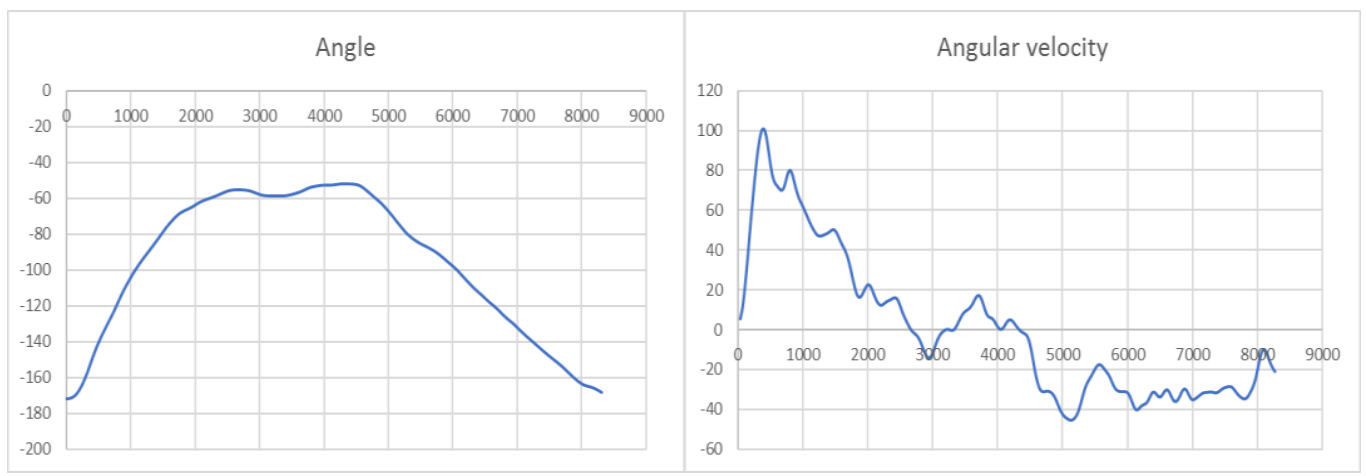

Figure 3. Biomechanical representation of angle and angle variation in the forearm flexion and extension

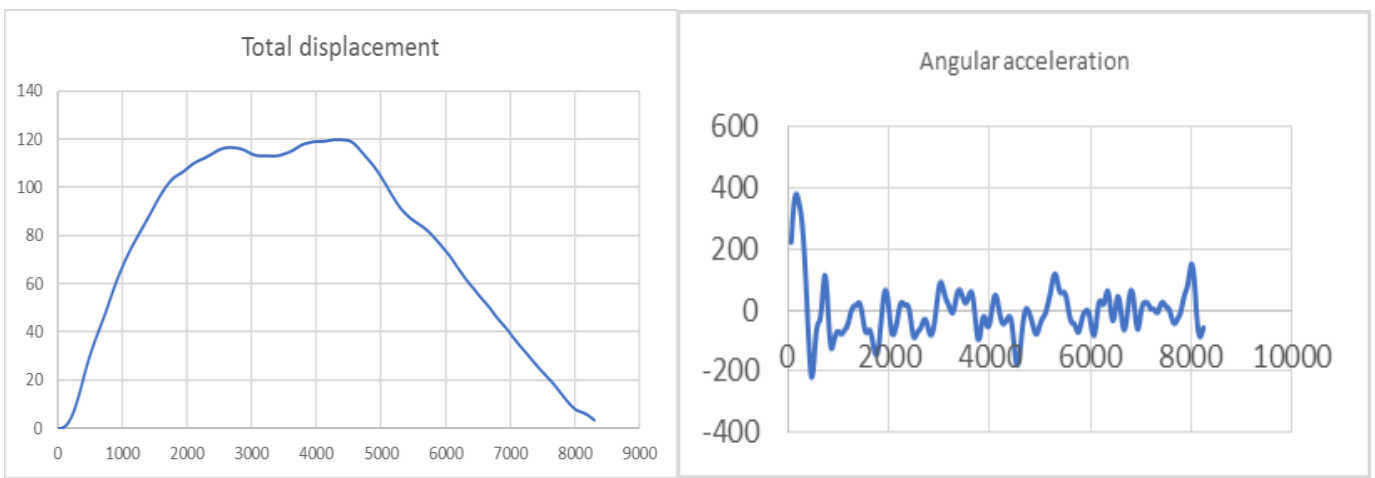

Figure 4. Representation of total displacement and angular acceleration in the forearm flexion and extension 

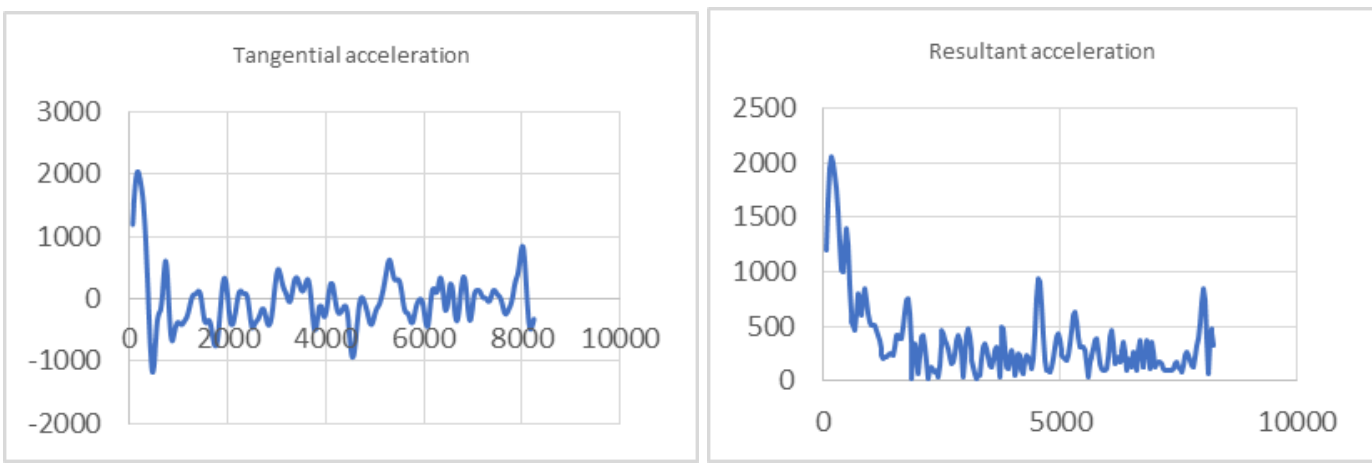

Figure 5. Biomechanical representation of tangential acceleration and resultant acceleration in the forearm flexion and extension

Table 1. Angular kinematics - from frame 0 to frame 2936

\begin{tabular}{ccccccc}
\hline $\begin{array}{c}\text { Time } \\
\text { (ms) }\end{array}$ & Angle & $\begin{array}{c}\text { Angular } \\
\text { velocity }\end{array}$ & $\begin{array}{c}\text { Total } \\
\text { displacement }\end{array}$ & $\begin{array}{c}\text { Angular } \\
\text { acceleration }\end{array}$ & $\begin{array}{c}\text { Tangential } \\
\text { acceleration }\end{array}$ & $\begin{array}{c}\text { Resultant } \\
\text { acceleration }\end{array}$ \\
\hline 0 & -172.137 & - & - & - & - & - \\
133 & -170.428 & 31.60931 & 1.70864 & 360.784 & 1945.261 & 1947.532 \\
267 & -162.887 & 79.62643 & 9.249729 & 306.9687 & 1656.076 & 1760.399 \\
400 & -150.228 & 100.7397 & 21.9092 & -53.3612 & -286.811 & 994.29 \\
534 & -138.264 & 76.69962 & 33.87264 & -128.569 & -690.502 & 883.6697 \\
667 & -128.611 & 70.02924 & 43.52572 & 4.533717 & 24.37134 & 460.7545 \\
801 & -118.605 & 80.16132 & 53.53246 & -11.664 & -62.6137 & 605.2943 \\
934 & -108.754 & 66.40366 & 63.38276 & -86.6033 & -463.857 & 620.5439 \\
1068 & -100.544 & 56.58437 & 71.59334 & -76.7874 & -410.621 & 507.8463 \\
1201 & -93.6089 & 48.20319 & 78.52818 & -39.5609 & -210.875 & 301.9869 \\
1335 & -87.2971 & 47.84128 & 84.83995 & 14.15625 & 75.09749 & 224.8272 \\
1468 & -80.7432 & 50.31888 & 91.39388 & -5.58731 & -29.475 & 234.9815 \\
1602 & -74.4365 & 42.65355 & 97.70061 & -65.3074 & -342.302 & 380.6181 \\
1735 & -69.4162 & 30.11858 & 102.7209 & -141.445 & -738.739 & 743.3527 \\
1869 & -66.5811 & 16.21989 & 105.556 & -2.64719 & -13.8167 & 27.66335 \\
2002 & -64.0052 & 22.63665 & 108.1318 & 7.69929 & 40.14199 & 61.52708 \\
2135 & -61.4147 & 14.42313 & 110.7224 & -60.6634 & -315.641 & 316.2062 \\
2269 & -59.7121 & 13.63339 & 112.4249 & 24.69449 & 128.3485 & 129.4512 \\
2402 & -57.7211 & 16.01217 & 114.4159 & 5.786743 & 30.04185 & 37.97628 \\
2536 & -55.9031 & 8.331842 & 116.234 & -84.0235 & -436.32 & 436.3657 \\
2669 & -55.425 & -0.34564 & 116.7121 & -43.4067 & -225.5 & 225.5 \\
2803 & -55.7691 & -5.69929 & 116.3679 & -71.1203 & -369.841 & 369.8528 \\
2936 & -57.2127 & -14.2206 & 114.9244 & -4.88721 & -25.462 & 31.40778 \\
\hline
\end{tabular}

Table 2. Angular kinematics - from frame 3003 to frame 5939

\begin{tabular}{ccccccc}
\hline $\begin{array}{c}\text { Time } \\
\text { (ms) }\end{array}$ & Angle & $\begin{array}{c}\text { Angular } \\
\text { velocity }\end{array}$ & $\begin{array}{c}\text { Total } \\
\text { displacement }\end{array}$ & $\begin{array}{c}\text { Angular } \\
\text { acceleration }\end{array}$ & $\begin{array}{c}\text { Tangential } \\
\text { acceleration }\end{array}$ & $\begin{array}{c}\text { Resultant } \\
\text { acceleration }\end{array}$ \\
\hline 3003 & -58.118 & -11.3403 & 114.019 & 79.72296 & 415.5503 & 415.7149 \\
3136 & -58.869 & -1.58346 & 113.268 & 36.1606 & 188.5327 & 188.5328 \\
3270 & -58.8982 & -0.23029 & 113.2389 & -8.48763 & -44.2485 & 44.24855 \\
3403 & -58.7842 & 4.35532 & 113.3528 & 65.99306 & 344.377 & 344.3814 \\
3537 & -57.7283 & 10.01715 & 114.4088 & 24.39081 & 127.4696 & 127.7978 \\
3670 & -56.0317 & 16.43253 & 116.1053 & 41.62065 & 218.25 & 219.6447 \\
3804 & -53.9834 & 9.948826 & 118.1537 & -90.7949 & -477.498 & 477.5845 \\
3937 & -53.1041 & 4.800391 & 119.033 & -42.0808 & -220.6 & 220.6102 \\
\hline
\end{tabular}




\begin{tabular}{ccccccc}
\hline \hline & & & & & \\
\hline 4071 & -52.8912 & 0.441131 & 119.2458 & 24.63083 & 128.9768 & 128.9768 \\
4204 & -52.4479 & 4.869427 & 119.6892 & -13.417 & -70.4408 & 70.47431 \\
4338 & -52.1216 & -0.26401 & 120.0154 & -32.3884 & -169.645 & 169.6453 \\
4471 & -52.3762 & -4.50388 & 119.7608 & -85.9852 & -449.714 & 449.7179 \\
4605 & -54.2854 & -25.5304 & 117.8517 & -132.56 & -694.397 & 696.949 \\
4738 & -58.3106 & -31.0014 & 113.8264 & 5.066657 & 26.56834 & 91.8845 \\
4872 & -62.5106 & -33.5646 & 109.6264 & -56.9794 & -299.15 & 316.4605 \\
5005 & -67.6414 & -42.821 & 104.4957 & -43.8185 & -230.459 & 285.3802 \\
5138 & -73.6064 & -45.5523 & 98.53069 & 6.696229 & 35.33688 & 194.355 \\
5272 & -79.37 & -38.0456 & 92.76701 & 110.9864 & 587.4853 & 602.5126 \\
5405 & -83.461 & -25.2656 & 88.67603 & 58.53458 & 310.8572 & 316.438 \\
5539 & -86.3235 & -17.9921 & 85.81352 & 28.63462 & 152.4649 & 155.4043 \\
5672 & -88.8084 & -21.0331 & 83.32869 & -43.0654 & -229.793 & 233.4575 \\
5806 & -92.1285 & -29.3384 & 80.00856 & -49.8138 & -266.589 & 278.4485 \\
5939 & -96.2482 & -31.2017 & 75.88885 & -0.75156 & -4.04148 & 91.46061 \\
\hline
\end{tabular}

Table 3. Angular kinematics - from frame 6006 to frame 8308

\begin{tabular}{ccccccc}
\hline $\begin{array}{c}\text { Time } \\
\text { (ms) }\end{array}$ & Angle & $\begin{array}{c}\text { Angular } \\
\text { velocity }\end{array}$ & $\begin{array}{c}\text { Total } \\
\text { displacement }\end{array}$ & $\begin{array}{c}\text { Angular } \\
\text { acceleration }\end{array}$ & $\begin{array}{c}\text { Tangential } \\
\text { acceleration }\end{array}$ & $\begin{array}{c}\text { Resultant } \\
\text { acceleration }\end{array}$ \\
\hline 6006 & -98.3335 & -31.897 & 73.8036 & -37.544 & -202.658 & 224.1829 \\
6139 & -103.204 & -40.383 & 68.93275 & -9.15786 & -49.7895 & 162.5584 \\
6273 & -108.388 & -37.3701 & 63.74954 & 22.72365 & 124.1669 & 182.0866 \\
6406 & -112.955 & -31.3343 & 59.18236 & -0.88497 & -4.85405 & 94.11731 \\
6540 & -117.363 & -32.676 & 54.77401 & 43.74184 & 240.4509 & 261.3625 \\
6673 & -121.509 & -33.3765 & 50.62822 & -64.0146 & -352.394 & 368.2891 \\
6807 & -126.238 & -33.4158 & 45.8989 & 64.20477 & 354.3843 & 370.3503 \\
6940 & -130.342 & -32.4549 & 41.79465 & -62.2477 & -344.949 & 359.6786 \\
7074 & -134.971 & -34.0225 & 37.16562 & 24.97516 & 138.7733 & 178.4919 \\
7207 & -139.304 & -31.5645 & 32.83353 & 4.015261 & 22.37262 & 99.43923 \\
7341 & -143.5 & -31.7465 & 28.63708 & -5.31895 & -29.7089 & 102.6427 \\
7474 & -147.64 & -29.5056 & 24.49726 & 18.14091 & 101.5564 & 132.4734 \\
7608 & -151.486 & -28.9206 & 20.65128 & -21.0366 & -118.052 & 143.6908 \\
7741 & -155.678 & -33.8561 & 16.4586 & -25.7328 & -144.891 & 183.5267 \\
7875 & -160.266 & -32.6187 & 11.87073 & 53.78155 & 303.3519 & 320.9259 \\
8008 & -163.942 & -19.5545 & 8.195448 & 150.6024 & 849.2695 & 850.103 \\
8141 & -165.565 & -11.5236 & 6.571844 & -67.7753 & -381.362 & 381.5848 \\
8308 & -168.557 & - & 3.580481 & - & - & - \\
\hline
\end{tabular}

\section{Discussion}

Sports biomechanics is now generally carried out using wearable sensors that enable non-invasive data acquisition during motion execution (Taborri et al., 2016). Besides, wearable sensors enable sporting activities to be carried out in the natural environment, overcoming laboratory tests' environmental constraints, such as using the optoelectronic 3D system, which is still considered the gold standard for motion analysis (Taborri et al., 2016; van der Kruk and Reijne, 2018). Inertial sensors (Lee and James, 2015; Kinnunen et al., 2019; Gopfert et al., 2017), force sensors (Lee et al., 2017; Buckeridge et al., 2015; Kos and Umek, 2018a), and electromyography probes (Brochner et al., 2018; Cruz Ruiz et al., 2015) are commonly used to quantify kinematics, kinetics, and muscle activity objectively and unobtrusively during sports activities. One promising direction in using wearable sensors is real-time biofeedback systems (Kos and Umek, 2018b) that can provide athletes and/or coaches with simultaneous augmented feedback information (Kos and Umek, 2019; Umek and Kos, 2016; Kos et al., 
2019). To perform advanced experiments that gave a much better understanding of joint kinematics and tissue function during walking, running, and other daily living activities, more sophisticated equipment and analyses were available (Innocenti, 2018).

Investigation in motor control was previously restricted to lab-established evaluations of specific neurons, muscles, or joints, grabbed from insignificant sampling. In the heritage, the practicability of considerable size, the multivariate investigation was legitimately constrained by overreliance on massive, expensive, outside broadcast gadgets, such as optic motion capture networks (Nordin et al., 2017). Today, full-body kinematic recordings are becoming increasingly common, employing body-sported inertial determining divisions, cordless electromyography (EMG), electroencephalography (EEG), and operational near-infrared spectroscopy (fNIRS) networks, and electrode assortments for neural system broadcasts (Nordin et al., 2017).

Some research indicated that for the 2.5 to 3 seconds of a more extended test, muscles that can hold an isometric contraction for a short time could not retain the contraction (Conable, 2010). "Because many examiners in practice use tests of 1 second or less (Vasilyeva, 2004), muscle weaknesses that develop later may be missed, with the differences observed being possible (differences in duration of tests may well be between" patient-started "and" examiner-started "tests).

In clinical movement analysis, muscle contraction kinematics and muscle force analysis are not yet well established, but there are considerable advantages. In surgical planning for cerebral palsy patients, information about muscle length changes during gait can help (Arnold et al., 2006).

\section{Conclusions}

The study's hypothesis has been confirmed, and by using kinetic and biomechanical analysis software, Kinovea, version 0.9.3., it was improved the teaching process in the practical work on Biomechanics and Kinesiology discipline.

Also, the students' feedback was positive, and by merely using Kinovea software, it was able to translate into practice the concepts accumulated in the course, notions about biomechanics, kinesiology, and angular kinematics (angular velocity, total displacement, angular acceleration, tangential acceleration, resultant acceleration).

\section{References}

Arnold, A. S., Liu, M. Q., Schwartz, M. H., Ounpuu, S, Delp, S. L. (2006). The role of estimating muscletendon lengths and velocities of the hamstrings in the evaluation and treatment of crouch gait. Gait Posture, 23, 273-281. https://doi.org/10.1016/j.gaitpost.2005.03.003.

Bailey, R., Cope, E., Parnell, D. (2015). Realising the Benefits of Sports and Physical Activity: the Human Capital Model Materializando los beneficios del deporte y la actividad física: El modelo de capital humano. Retos.

Barrios, J. A., Crossley, K. M., Davis, I. S. (2011). Gait retraining to reduce the knee adduction moment through real-time visual feedback of dynamic knee alignment. J Biomech, 43, 2208-2213. https://doi.org/10.1016/j.jbiomech.2010.03.040.

Brøchner, N. N., Hug, F., Guével, A., Colloud, F., Lardy, J., Dorel, S. (2018). Changes in motor coordination induced by local fatigue during a sprint cycling task. Medicine and Science in Sports and Exercise, 50(7), 1394-1404. https://doi.org/10.1249/MSS.0000000000001572. 
Buckeridge, E., Levangie, M. C., Stetter, B., Nigg, S. R., Nigg, B. M. (2015). An on-ice measurement approach to analyse the biomechanics of ice hockey skating. PLoS One., 10(5), e0127324. https://doi.org/10.1371/journal.pone.0127324

Conable, K. M. (2010). Intraexaminer comparison of applied kinesiology manual muscle testing of varying durations: a pilot study. Journal of chiropractic medicine, 9(1), 3-10. https://doi.org/10.1016/j.jcm.2009.12.005

Cruz Ruiz, A. L., Pontonnier, C., Sorel, A., Dumont, G. (2015). Identifying representative muscle synergies in overhead football throws. Computer Methods in Biomechanics and Biomedical Engineering, 18(sup1), 1918-1919. https://doi.org/10.1080/10255842.2015.1070581.

Delp, S. L., Anderson, F. C., Arnold, A. S., Loan, P., Habib, A., John, C. T., Guendelman, E., Thelen, D. G. (2007). OpenSim: open-source software to create and analyze dynamic simulations of movement. IEEE Trans Biomed Eng., 54(11), 1940-1950. https://doi.org/10.1109/TBME.2007.901024.

Erdemir, A., McLean, S., Herzog, W., van den Bogert, A. J. (2007). Model-based estimation of muscle forces exerted during movements. Clin Biomech., 22(2), 31-154. https://doi.org/10.1016/j.clinbiomech.2006.09.005.

Gilchrist, P., Wheaton, B. (2016). The social benefits of informal and lifestyle sports: a research agenda. International Journal of Sport Policy and Politics, 9(1), 1-10. https://doi.org/10.1080/19406940.2017.1293132.

Göpfert, C., Pohjola, M. V., Linnamo, V., Ohtonen, O., Rapp, W., Lindinger, S. J. (2017). Forward acceleration of the centre of mass during ski skating calculated from force and motion capture data. Sports Engineering, 20(2), 141-153. https://doi.org/10.1007/s12283-016-0223-9.

Heintz, S., Gutierrez-Farewik, E. M. (2007). Static optimization of muscle forces during gait in comparison to EMG-to-force processing approach. Gait Posture, 26(2), 279-288. https://doi.org/ 10.1016/j.gaitpost.2006.09.074.

Hewett, T. E., Bates, N. A. (2017). Preventive Biomechanics: A Paradigm Shift With a Translational Approach to Injury Prevention. The American journal of sports medicine, 45(11), 2654-2664. https://doi.org/10.1177/0363546516686080

Hewett, T. E., Myer, G. D., Ford, K. R. (2005). Biomechanical Measures of Neuromuscular Control and Valgus Loading of the Knee Predict Anterior Cruciate Ligament Injury Risk in Female Athletes: A Prospective Study. Am. J. Sports Med., 33(4), 492-501.

Innocenti, B. (2018). Biomechanics: a fundamental tool with a long history (and even longer future!). Muscles, ligaments and tendons journal, 7(4), 491-492. https://doi.org/10.11138/mltj/2017.7.4.491

Kiehn, O. (2016). Decoding the organization of spinal circuits that control locomotion. Nat Rev Neurosci, 17(4), 224. https://doi.org/10.1038/nrn.2016.9.

Kinnunen, H., Häkkinen, K., Schumann, M., Karavirta, L., Westerterp, K. R., Kyröläinen, H. (2019). Training-induced changes in daily energy expenditure: methodological evaluation using wrist-worn accelerometer, heart rate monitor, and doubly labeled water technique. PLoS One., 14(7), e0219563). https://doi.org/10.1371/journal.pone.0219563

Kos, A., Milutinović, V., Umek, A. (2019). Challenges in wireless communication for connected sensors and wearable devices used in sport biofeedback applications. Future Generation Computer Systems, 92, 582-592. https://doi.org/10.1016/j.future.2018.03.032.

Kos, A., Umek, A. (2018a). Biomechanical Biofeedback Systems and Applications. Cham: Springer International Publishing.

Kos, A., Umek, A. (2018b). Smart sport equipment: SmartSki prototype for biofeedback applications in skiing. Personal and Ubiquitous Computing, 22(3), 535-544. https://doi.org/10.1007/s00779-018-1146-1.

Kos, A., Umek, A. (2019). Wearable sensor devices for prevention and rehabilitation in healthcare: swimming exercise with real-time therapist feedback. IEEE Internet of Things Journal, 6(2), 13311341. https://doi.org/10.1109/JIOT.2018.2850664.

Lanuza, G. M., Gosgnach, S., Pierani, A., Jessell, T. M., Goulding, M. (2004). Genetic identification of spinal interneurons that coordinate left-right locomotor activity necessary for walking movements. Neuron., 42(3), 375-386. https://doi.org/10.1016/S0896-6273(04)00249-1.

Lee, J., James, D. A. (2015). The inertial sensor: a base platform for wider adoption in sports science applications Wearable technology development View project Human Technologies View project. Journal of Fitness Research, 4(1), 13-20. 
Lee, S., Kim, K., Kim, Y. H., Lee, S. (2017). Motion anlaysis in lower extremity joints during ski carving turns using wearble inertial sensors and plantar pressure sensors. IEEE International Conference on Systems, Man, and Cybernetics (SMC), pp. 695-698.

Nordin, A. D., Rymer, W. Z., Biewener, A. A., Schwartz, A. B., Chen, D., Horak, F. B. (2017). Biomechanics and neural control of movement, 20 years later: what have we learned and what has changed? Journal of neuroengineering and rehabilitation, 14(1), 91. https://doi.org/10.1186/s12984-017-0298-y

Shull, P. B., Lurie, K. L., Cutkosky, M. R., Besier, T. F. (2011). Training multi-parameter gaits to reduce the knee adduction moment with data-driven models and haptic feedback. J Biomech., 44(8), 16051609. https://doi.org/10.1016/j.jbiomech.2011.03.016.

Taborri, J., Keogh, J., Kos, A., Santuz, A., Umek, A., Urbanczyk, C., van der Kruk, E., Rossi, S. (2020). Sport Biomechanics Applications Using Inertial, Force, and EMG Sensors: A Literature Overview. Applied bionics and biomechanics. https://doi.org/10.1155/2020/2041549

Taborri, J., Palermo, E., Rossi, S. (2019). Automatic detection of faults in race walking: a comparative analysis of machine-learning algorithms fed with inertial sensor data. Sensors, 19(6), 1461. https://doi.org/10.3390/s19061461.

Taborri, J., Palermo, E., Rossi, S., Cappa, P. (2016). Gait partitioning methods: a systematic review. Sensors, 16(1), 66. https://doi.org/10.3390/s16010066.

Teran-Yengle, P., Birkhofer, R., Weber, M. A., Patton, K., Thatcher, E., Yack, H. J. (2011). Efficacy of gait training with real-time biofeedback correcting knee hyperextension patterns in young women. Journal of Orthopaedic and Sports Physical Therapy, 41(12), 948-52. https://doi.org/10.2519/jospt.2011.3660

Umek, A., Kos, A. (2016). The role of high-performance computing and communication for real-time biofeedback in sport. Mathematical Problems in Engineering. https://doi.org/10.1155/2016/4829452.

Van den Bogert, A. J., Geijtenbeek, T., Even-Zohar, O., Steenbrink, F., \& Hardin, E. C. (2013). A real-time system for biomechanical analysis of human movement and muscle function. Medical \& biological engineering \& computing, 51(10), 1069-1077. https://doi.org/10.1007/s11517-013-1076-z

Vasilyeva, L. F. (2004). Clinical and experimental substantiation of the functional muscle weakness phenomenon. Proceedings of the International College of Applied Kinesiology Annual Meeting, Rome, Italy Shawnee Mission, KS:ICAK.

Zatsiorsky, V. M., Fortney, V. L. (2007). Sport biomechanics 2000. Journal of Sports Sciences, 11(4), 279283. https://doi.org/10.1080/02640419308729997. 